\title{
Influence of Seawater on the Degree of Entrainment in the Flotation of a Synthetic Copper Ore
}

\author{
Leopoldo Gutierrez ${ }^{1}$ * , Fernando Betancourt ${ }^{1}$, Lina Uribe ${ }^{2}$ and Miguel Maldonado ${ }^{3}$ \\ 1 Departamento de Ingeniería Metalúrgica, Universidad de Concepción, Concepción 4070371, Chile; \\ fbetancour@@udec.cl \\ 2 Escuela de Ingeniería Civil de Minas, Universidad de Talca, Talca 9170020, Chile; luribe@utalca.cl \\ 3 Departamento de Ingeniería Metalúrgica, Universidad de Santiago de Chile, Santiago 3460000, Chile; \\ miguel.maldonado.s@usach.cl \\ * Correspondence: lgutierrezb@udec.cl
}

Received: 25 May 2020; Accepted: 7 July 2020; Published: 9 July 2020

\begin{abstract}
Froth flotation is a process in which hydrophobic particles attach to bubbles forming particle-bubble aggregates, which are transported to the top section of the cell where they overflow to form the concentrate. Particles also reach the concentrate by entrainment, which is a non-selective process that leads to low concentrate grades. The objective of this work was to study and compare the degree of entrainment measured using three methods, in fresh and seawater, and using methyl isobutyl carbinol (MIBC) and DF-250 as frothers. The experimental results indicated that the degree of entrainment decreased in seawater. Besides, water recovery was lower in the experiments with seawater regardless of the frother that was used in the experiments, which correlated with the observed low degrees of entrainment. It is proposed that the reduction of entrainment and water recovery in seawater can be explained by a reduction of air recovery and/or more bubble coalescence in the froth. It is also proposed that surfactant diffusion/convection from the lamellae to the Plateau borders in the froth is reduced in seawater, which reduces the surface tension gradients, and thus the restoring liquid flow from the Plateau borders to the lamellae.
\end{abstract}

Keywords: flotation; seawater; entrainment; frothers

\section{Introduction}

Froth flotation is a widely used concentration process that is driven by the differences in the surface properties of valuable and gangue particles. Hydrophobic particles attach to ascending bubbles forming particle-bubble aggregates, which are transported to the top section of the cell to form the concentrate. The mechanism by which particles report to the concentrate attached to bubbles is referred to as "true flotation", but there are also particles that, irrespective of their surface properties (hydrophobicity/hydrophilicity), are pushed up by the swarm of ascending bubbles, which is called entrainment. The recovery of mineral particles by entrainment is a non-selective process as both hydrophobic and hydrophilic particles have chances of being recovered, which negatively affects the effective separation of valuable and gangue particles and reduces concentrate grades [1]. Previous studies showed that the degree of entrainment is proportional to the amount of water carried to the concentrate [1-7]. Therefore, to understand the phenomena that drive entrainment in flotation, it is necessary to analyze the physical phenomena that explain the variations of the flow of water that overflows the flotation cell and is carried into concentrate. 


\subsection{Water Recovery, Froth Stability, and Entrainment}

Wang et al., 2015 [2] described the mechanisms by which particles reach the concentrate in a flotation cell, that is, (1) transfer of particles from the pulp to the froth by true flotation and (2) from the froth to the concentrate by true flotation, (3) transfer of particles from the pulp to the froth by entrainment and (4) from the froth to the concentrate by entrainment, and finally (5) transport of particles from the froth to the pulp by drainage of detached and entrained particles. Smith and Warren 1989 [1] proposed the so-called bubble swarm theory to explain how water reaches a position just underneath the pulp/froth interface. According to this theory, bubbles rise to the layer below the froth where liquid can be squeezed out and drained back to the collection zone between the rising swarm of bubbles. As more bubbles rise to the position just below the pulp/froth interface, more water is pushed. A fraction of the water located below the pulp/froth interface flow through the froth to finally be recovered in the concentrate, thus froth behavior is key to understand water recovery and entrainment.

The froth behavior was studied before in order to understand the main variables that explain the flow of liquid in the froth [7-10]. The recovery of liquid from flowing foams was thoroughly studied by Neethling et al., 2003 [8]. These authors developed and validated a model based on the physics of foams to describe the flow of liquid through and out of the foam. The results of this work showed that water recovery decreases as bubble size increases in the foam as a result of more bubble coalescence, which is more relevant as foam height increases. The authors indicated that the effect of coarsening of bubble size is more important than foam height to explain the changes in water recovery. Later publications showed that the amount of water that reports into the concentrate strongly depends on froth stability, which is closely related to coalescence of bubbles in the froth and bursting of bubbles as they get to the lip cell [7-10]. In the flotation process, the bubble coalescence and bursting phenomena occur because of the lamellae breaking, which results in the detachment of particles from the bubble surfaces, particles that report into the Plateau borders and finally into the pulp [8,9]. The same authors quantified the bubbles bursting as the fraction of air entering the froth that finally overflows the cell as unburst bubbles, which was referred to as $\alpha$ or air recovery [8]. Neethling et al., 2003b [9] reported results that indicated, for foams in which $\alpha>0.5$, that the liquid content of the overflowing foam decreases with $\alpha$ and the amount of foam that is recovered increases in such a way that the amount of liquid that overflows is constant; in contrast, if $\alpha<0.5$, the liquid content in the foam increases as $\alpha$ decreases, but the amount of foam collected decreases, which results in less liquid overflowing the cell. These results indicate that the degree of entrainment in flotation is strongly related to froth stability. On the basis of the previous work [7-10], Neethling and Cilliers 2009 [7] developed a theoretical froth model for entrainment that considered liquid motion/content, particle settling, and dispersion in the froth. They showed that air recovery and air rate affect the entrainment factor and liquid velocity is strongly influenced by the change in bubble size in the foam, which counteracts particles settling.

The drainage velocity of liquid through the Plateau borders $j_{D}$ was proposed to be function of gravity, bubble radius $r$, liquid density, concentration of liquid in the foam $\varepsilon$, and viscosity $\eta$ [11-13]. In the case of rigid Plateau borders, the drainage is given by Equation (1).

$$
j_{D}=\frac{C_{1} \varepsilon r^{2} \rho g}{\eta}
$$

where $C_{1}$ is a constant. In the case that Plateau borders exhibit surface shear viscosity, Equation (1) is modified to obtain Equation (2) by introducing the Boussinesq number Bo defined by $B o=\frac{\mu_{S}}{\mu r}$, where $\mu_{S}$ is the surface shear viscosity and $C_{2}$ and $C_{3}$ are constants.

$$
j_{D}^{\mu_{S}}=\frac{C_{1} \varepsilon_{l} r^{2} \rho g}{\mu}\left(1+\frac{C_{2} B o^{-0.5}}{C_{3}+B o^{0.628}}\right)
$$


These studies indicate that the drainage velocity of liquid through the Plateau borders decreases as shear viscosity increases, which is something to be considered to explain the flow of liquid recovered in the concentrate.

As discussed previously, the amount of water that reports into the concentrate strongly depends on bubble size in the froth, which is related to bubble coalescence [7-10]. Bubble coalescence also depends on the stability of the lamellae, which is also affected by the so-called Gibbs-Marangoni effects. It is well established that foams are formed by three zones, that is, a bubble zone, kugelschaum or sphere zone, and polyederschaum or polyhedral zone [14] (see Figure 1a). In the bubble zone, bubbles move freely upwards and the gas hold-up is relatively low; in the sphere zone, bubbles still display a close spherical geometry and are separated by thick films of liquid; while in the polyhedral zone bubbles, are separated by thin flat liquid films or lamellae, and the junction points of the interconnecting channels existing between the bubbles are the Plateau borders [6]. In the case of flotation froths, the largest amount of liquid is found in the Plateau borders [10]. As can be seen in Figure 1b, owing to the curvature of the air/liquid interface in the Plateau borders, the liquid pressure in the lamellae $\left(P_{L}\right)$ is higher than the pressure in the Plateau borders $\left(P_{p b}\right)$, thus liquid mass transfer $\left(L^{*}\right.$ in Figure $\left.1 b\right)$ takes place towards the Plateau borders [15]. Variables such as liquid viscosity and electrostatic repulsive forces existing between the air/liquid interfaces, among others, affect the drainage rate. For small film thicknesses, electrostatic repulsive forces stabilize the lamellae and improve foam stability. The liquid drainage $L^{*}$ displaces surfactant molecules from the lamellae to the Plateau borders, which induces a surface tension gradient, and the surface tension in the lamellae increases with respect to the surface tension in the Plateau borders. The heterogeneous concentration of surface-active agents at the air/liquid interface induces liquid mass transfer from the Plateau borders to the lamellae ( $p b^{*}$ in Figure $1 b$ ), which is explained by the so-called Gibbs-Marangoni effects (resorting forces), which increase the thickness of the film, and thus improves foam stability [14]. In the case of a froth (three-phase system), the behavior of the air/liquid interface and froth stability are strongly affected by the presence of the hydrophobic solids. Froth stability increases as the hydrophobicity of the particles that adhere to the air/liquid interface increases up to a critical contact angle, after which destabilization occurs [15]. The presence of hydrophobic particles changes the curvature of the air/liquid interface, which causes a reduction in the pressure difference between the Plateau border and the lamellae. As a result, the thinning rate of the lamellae decreases and froth stability increases. It was also proposed that the presence of particles at the air/liquid interface hinders the liquid drainage towards the Plateau borders, thus stabilizing the froth [15]. The steric interaction resulting from the presence of particles in the bubbles surface also plays an important role in reducing coalescence [10].

a)

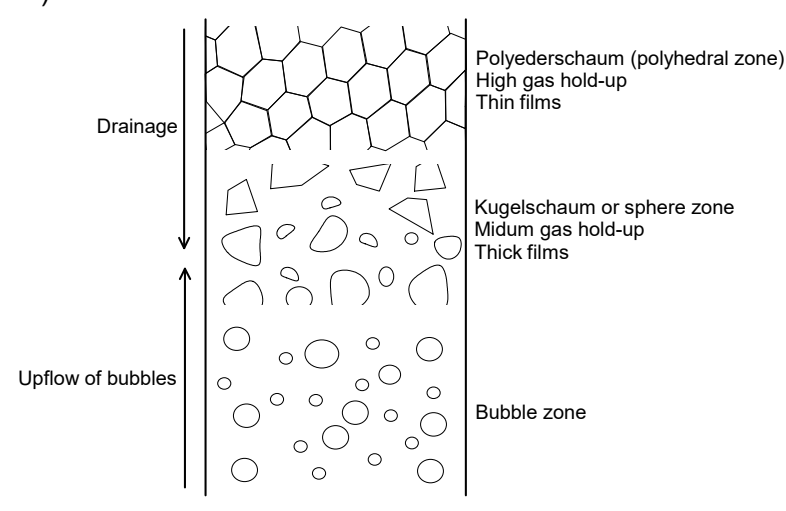

b)

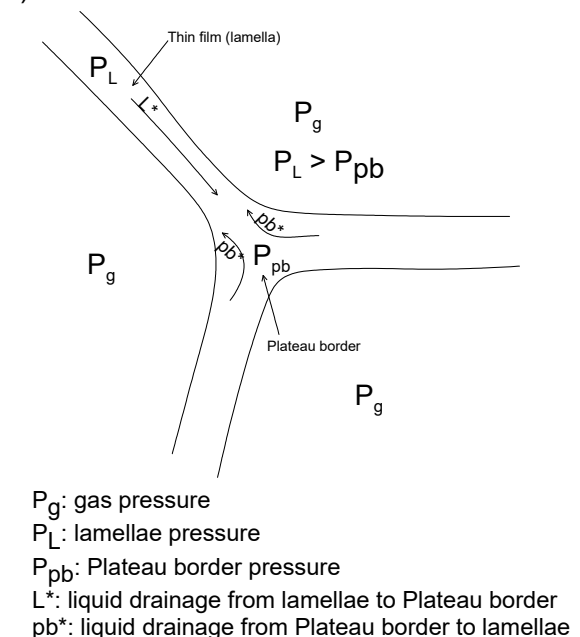

Figure 1. (a) Foam structure (adapted from Pugh 1996 [14]) and (b) phenomena occurring in the thin film and Plateau border. 


\subsection{Methods to Quantify Entrainment}

The degree of entrainment was previously related to water recovery by several authors [16-19] and was quantified in different ways. Trahar [17] in 1981 proposed to characterize entrainment by doing the flotation experiment with frother only. The method (Method 1 in this work) assumes that the degree of entrainment is the same in the tests carried out only with frother and the other one with both the collector and frother. Trahar 1981 [17] proposed to plot metal recovery versus the size of the floated particles and quantify entrainment as a difference between the recovery obtained using the frother only, and simultaneously both the frother and collector.

In the Warren's approach [18] (Method 2 in this work), introduced in 1985, the overall recovery of valuable particles $\varepsilon_{V}$ was considered to be comprised of two parts, that is, an amount due to true flotation $\varepsilon_{\text {true }}$ and the recovery due to entrainment $e_{V} \varepsilon_{W}$ :

$$
\varepsilon_{V}=\varepsilon_{\text {true }}+e_{V} \varepsilon_{W}
$$

where $e_{V}$ is the entrainment factor for hydrophobic valuable mineral, and $\varepsilon_{W}$ is the cumulative water recovery. The recovery of gangue $\varepsilon_{G}$ can also be correlated with water recovery:

$$
\varepsilon_{G}=e_{G} \varepsilon_{W}
$$

where $e_{G}$ is the entrainment factor for hydrophilic gangue mineral. Because, in Method 2, recovery is plotted versus water recovery, the flotation tests must be carried out varying water recovery. As pointed out by Warren [18], water recovery can be varied by changing one or more of the following parameters: rate of froth removal, froth depths, area of pulp surface available for froth formation, and height of cell lip. For each mineral system, hydrophobicity was kept constant by maintaining the same chemical environment, that is, $\mathrm{pH}$, type, and concentration of collector, frother, and depressant.

According to the method by Ross 1990 [19] (Method 3 in this work), the degree of entrainment $X(t)$ is defined as presented in Equation (5), where $E(t)$ and $\varepsilon_{W}(t)$ are the cumulative masses (g) of entrained solids and water recovered in a single flotation test after a time interval $t$, and $C_{W}$ and $C_{M}$ are the corresponding concentrations (g/L of pulp) of water and solid species.

$$
X(t)=\frac{E(t) C_{W}(t)}{\varepsilon_{W}(t) C_{M}(t)}
$$

As can be deduced from Equation (5), for constant concentrations of solids and water in the pulp, the entrainment factor $X(t)$ can be visualized as a factor that, when multiplied by the mass of water recovered, the obtained result is the mass of solids entrained. The cell cumulative recovery $Y(t)$, including both true flotation and entrainment, is expressed as in Equation (6).

$$
Y(t)=\frac{R(t) C_{W}(t)}{\varepsilon_{W}(t) C_{M}(t)}
$$

where $R(t)$ is the overall mass of solids recovered in the concentrate after the time interval $t$. The method assumes that that after a long flotation time $Y(t)$ tends to $X(t)$.

$$
\lim _{t \rightarrow \infty} Y(t)=X(t)
$$

Then, at long flotation times, $Y(t)$ equals $X(t)$ and the entrainment can be approximated by a straight-line as described in Equation (8).

$$
X(t)=X(0)+b t
$$

where $X(0)$ is the entrainment factor at $t=0$, and $b$ is an empirical constant. The constant $b$ accounts for the fact that the degree of entrainment changes over time, which can be directly related to the loss of froth stability at longer flotation time as less hydrophobic particles report to the froth. 


\subsection{Seawater Flotation}

Nowadays, seawater offers a real solution for $\mathrm{Cu}$-Mo concentrators that are located in zones with limited resources of continental water. Seawater contains ions (e.g., $\mathrm{Na}^{+}, \mathrm{K}^{+}, \mathrm{Mg}^{2+}, \mathrm{Ca}^{2+}, \mathrm{SO}_{4}{ }^{2-}$, $\mathrm{Cl}^{-}$), which induce important changes on the surface properties of $\mathrm{Cu}$-Mo sulfides and thus on the flotation efficiency [19-24]. Previous studies showed that flotation of molybdenite from Cu-Mo sulfide ores in seawater is depressed as $\mathrm{pH}$ is increased to depress pyrite, which was explained by the heterocoagulation between magnesium hydroxo-complexes and molybdenite [25-28]. Later, it was shown that sodium hexametaphospate can disperse these precipitates from molybdenite and restore flotation [21]. Related studies showed that the flotation of chalcopyrite and enargite is depressed in the alkaline $\mathrm{pH}$ range and that this depression seems to depend on the prevailing pulp redox potential [22,23]. Most of the studies related to the impact of the use of seawater on the flotation of copper and molybdenum minerals deal with the effects of ions on the surface properties of the minerals. However, the impact of ions on air dispersion and frothing properties in the copper-molybdenum system still deserves further empirical and theoretical research.

The objective of this work is to study and compare the degree of entrainment (measured using the three abovementioned methods) in fresh and seawater, using methyl isobutyl carbinol (MIBC) and DF-250 as frothers.

\section{Materials and Methods}

\subsection{Samples and Reagents}

Flotation tests were conducted using an artificial copper ore $(0.8 \%$ of $\mathrm{Cu})$ that was prepared by mixing chalcopyrite and quartz. A high purity sample of chalcopyrite was obtained from Ward's Natural Science Establishment as mineralized rock specimens. X-Ray Diffraction (XRD) indicated that 99.2\% of this sample was chalcopyrite with minor amounts of quartz $(0.7 \%)$ and pyrite $(0.1 \%)$. The chemical assays indicated a composition of $34.4 \% \mathrm{Cu}, 30.0 \% \mathrm{Fe}$, and $34.8 \% \mathrm{~S}$. The sample of coarse quartz used to generate the artificial copper ore was obtained from Ward's Natural Science Establishment and XRD indicated that this was a nearly pure quartz sample (99.8\% purity). Sodium isobutyl xanthate (SIBX) and Aero MX-7017 obtained from Solvay USA were used as collectors at $20 \mathrm{~g} / \mathrm{t}$ each one. Commercial frothers methyl isobutyl carbinol (MIBC) and DF-250 were used at $50 \mathrm{~g} / \mathrm{t}$. A $0.01 \mathrm{M} \mathrm{NaCl}$ solution prepared using distilled water (electrical conductivity of $21.5 \mu \mathrm{S} / \mathrm{cm}$ ) and sodium chloride obtained from Merck was considered as Fresh Water. $\mathrm{NaCl}$ in fresh water was used as a supporting electrolyte, which helped to maintain the ionic strength constant as well as the $\mathrm{pH}$. Seawater was obtained from the coast of Concepcion, Chile.

\subsection{Quantifying Entrainment}

To quantify entrainment using the three previously described methods (Section 1.2), batch flotation tests were carried out using a 2.7 L EDEMET (Chile) automated flotation cell equipped with control loops to set the rate of froth removal, air flowrate, and water make-up during the tests. All the experiments were done at an air flowrate of $12 \mathrm{~L} / \mathrm{min}$, and keeping the froth depth at $1 \mathrm{~cm}$. The flotation tests were done using $1 \mathrm{~kg}$ sample of the artificial copper ore $(100 \%-2 \mathrm{~mm})$, which was initially ground to a P80 of $150 \mu \mathrm{m}$ in a Marcy laboratory ball mill using mild steel balls for $15 \mathrm{~min}$. The grinding product was then placed in the flotation cell and the solids content was adjusted to $32 \%$ by weight in all the experiments. The $\mathrm{pH}$ of the pulp was adjusted using lime and reagents were added at $20 \mathrm{~g} / \mathrm{t}$ SIBX and $20 \mathrm{~g} / \mathrm{t}$ MX-7017 (for the tests with collector), and $20 \mathrm{~g} / \mathrm{t}$ of frother MIBC or DF-250 depending on the tests. All the experiments were done considering a conditioning time of $2 \mathrm{~min}$ at $900 \mathrm{rpm}$ of agitation. The flotation tests were performed at $1200 \mathrm{rpm}$.

In the experiments following Method 1, batch flotation tests were carried out with and without collectors and setting the time of froth removal to $10 \mathrm{~s}$. The concentrates were collected at 1, 2, 4, 8, and $12 \mathrm{~min}$. After finishing the tests, the concentrates and tailings were weighed and dried to calculate 
water and solid recoveries. All the tests were performed in duplicates with an average standard error of $3 \%$.

Method 2 required a set of flotation tests that have to be carried out varying water recovery, which in this study was achieved by changing the rate of froth removal to 5, 10, 20, 30, 40, 60, and $90 \mathrm{~s}$. The flotation tests were conducted at $1200 \mathrm{rpm}$ for $12 \mathrm{~min}$ and the concentrates and tailings were weighed and dried to calculate water and solid recoveries. All the tests were performed in duplicates with an average standard error of $3 \%$.

Method 3 required only one flotation test, which was done setting the time of froth removal to $10 \mathrm{~s}$, and the concentrates were collected at times of 1, 2, 4, 8, and $12 \mathrm{~min}$. After finishing the tests, the concentrates and tailings were weighed and dried to calculate water and solid recoveries. All the tests were performed in duplicates with an average standard error of $2 \%$.

\section{Results}

\subsection{Results Method 1}

Figure 2 shows the cumulative solids recovered as a function of water recovered for MIBC and DF-250 frothers, varying $\mathrm{pH}$ and type of water. The experimental data indicate that the degree of entrainment (solids recovered with frother only) obtained at $1000 \mathrm{~g}$ of water recovered is lower in seawater, and that DF-250 generates more entrainment than MIBC in all the aqueous media. The results also show that, for a fixed flotation time of $12 \mathrm{~min}$ (last data point), the recovery of water is lower in the experiments with seawater for both frothers.
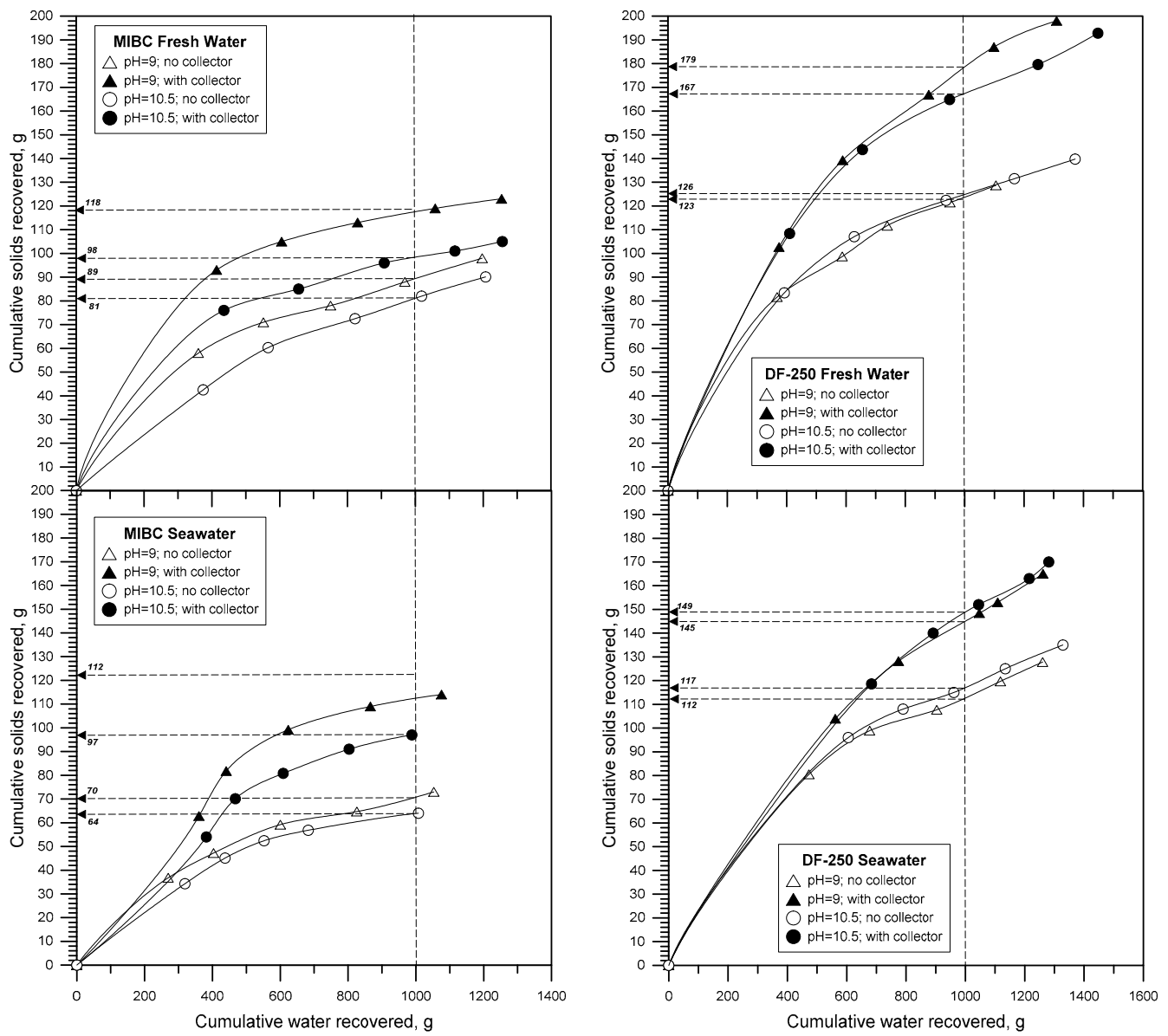

Figure 2. Cumulative solids recovered vs cumulative water recovered $\left(\varepsilon_{W}\right)$ using methyl isobutyl carbinol (MIBC) and DF-250, with and without collector (Method 1). 


\subsection{Results Method 2}

Figures 3 and 4 show the recoveries of valuable $\left(\varepsilon_{V}\right)$ and gangue particles $\left(\varepsilon_{G}\right)$ as a function of the cumulative water recovered using MIBC and DF-250 frothers, and varying $\mathrm{pH}$ and type of water. Table 1 summarizes the constants of the Warren's model. The results indicate that the entrainment factors $e_{V}$ and $e_{G}$ are in all the cases lower in seawater. At the same time, the masses of solids that report to the concentrate by true flotation also decrease in seawater at both $\mathrm{pH}$ values. All these results agree with the trends observed using Method 1.
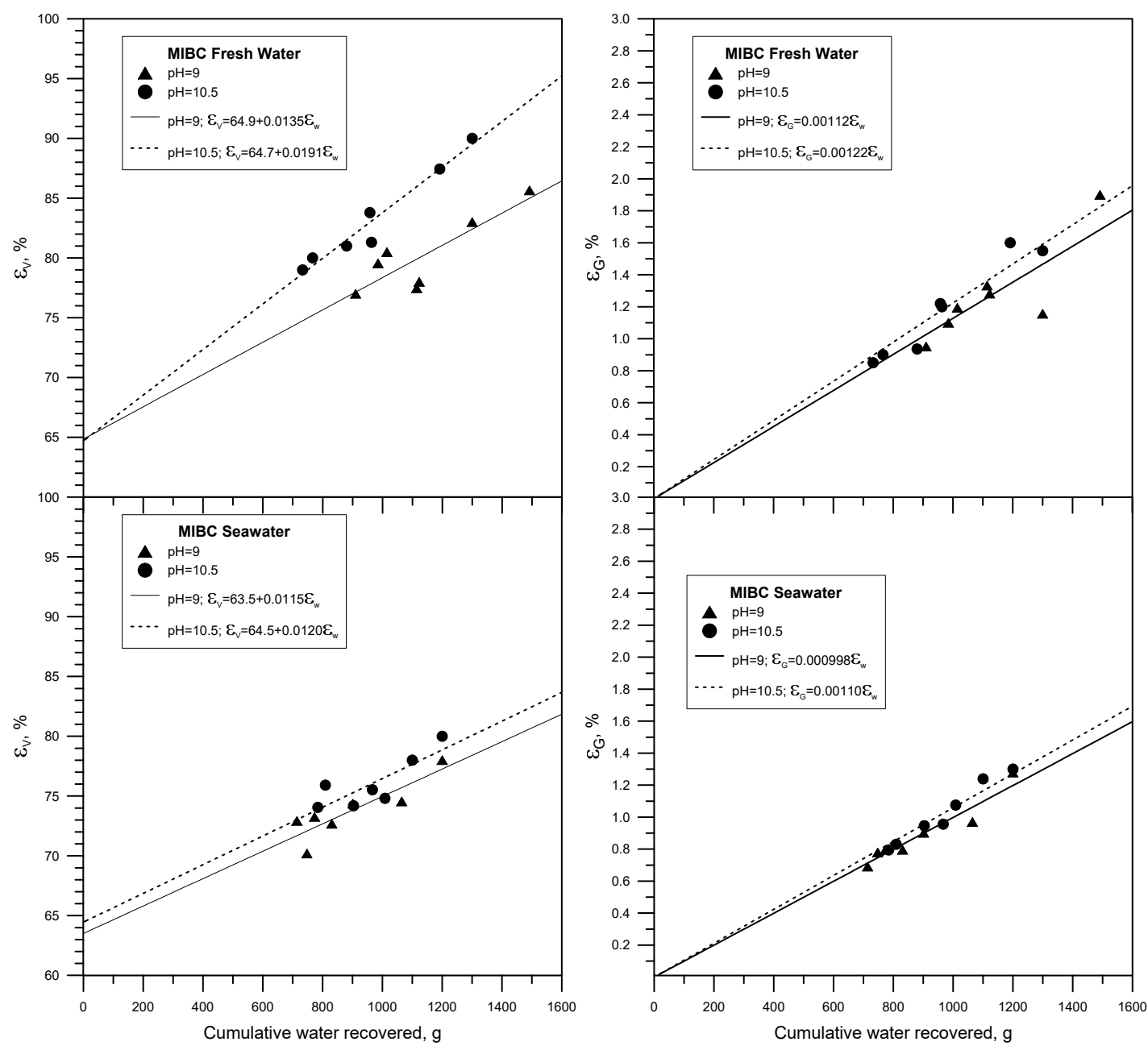

Figure 3. Recovery of valuable/gangue particles $\left(\varepsilon_{V} / \varepsilon_{G}\right)$ vs. cumulative water recovered $\left(\varepsilon_{W}\right)$ using MIBC.

Table 1. Constants of the Warren's model (Method 2). MIBC, methyl isobutyl carbinol.

\begin{tabular}{cccccc}
\hline Frother & Solution & $\mathbf{p H}$ & $\boldsymbol{\varepsilon}_{\text {true }}$ & $\boldsymbol{e}_{\boldsymbol{V}}$ & $\boldsymbol{e}_{\boldsymbol{G}}$ \\
\hline MIBC & Fresh Water & 9.0 & 64.9 & 0.0135 & 0.00112 \\
MIBC & Fresh Water & 10.5 & 64.7 & 0.0191 & 0.00122 \\
MIBC & Seawater & 9.0 & 63.5 & 0.0115 & 0.00100 \\
MIBC & Seawater & 10.5 & 64.5 & 0.0120 & 0.00110 \\
\hline Frother & Solution & $\mathbf{p H}$ & $\boldsymbol{\varepsilon}_{\text {true }}$ & $\boldsymbol{e}_{\boldsymbol{V}}$ & $\boldsymbol{e}_{\boldsymbol{G}}$ \\
\hline DF-250 & Fresh Water & 9.0 & 68.3 & 0.0162 & 0.00233 \\
DF-250 & Fresh Water & 10.5 & 69.8 & 0.0157 & 0.00284 \\
DF-250 & Seawater & 9.0 & 67.6 & 0.0145 & 0.00200 \\
DF-250 & Seawater & 10.5 & 67.1 & 0.0140 & 0.00259 \\
\hline
\end{tabular}



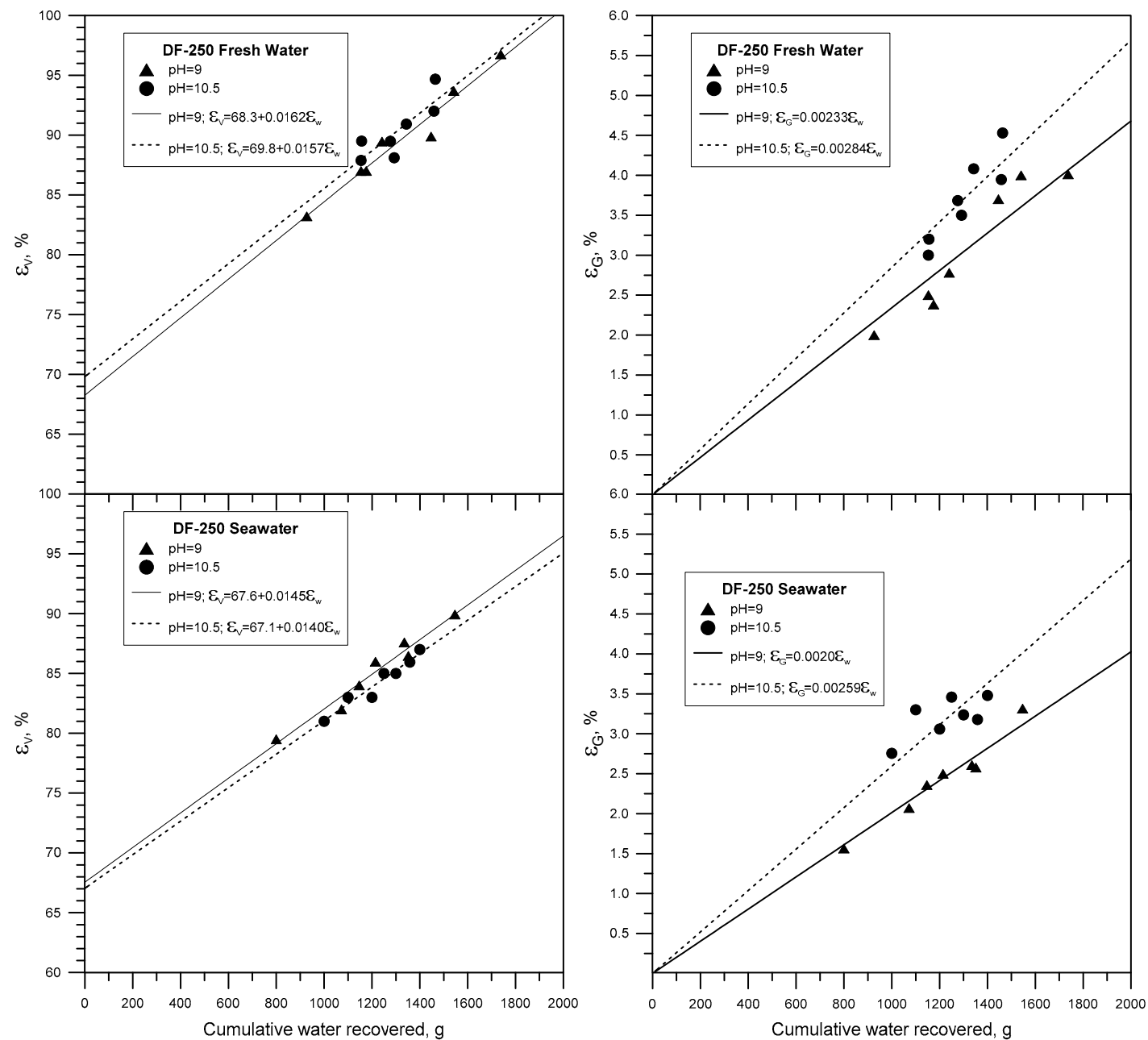

Figure 4. Recovery of valuable/gangue particles $\left(\varepsilon_{V} / \varepsilon_{G}\right)$ vs. cumulative water recovered $\left(\varepsilon_{W}\right)$ using DF-250.

\subsection{Results Method 3}

Figures 5 and 6 display $Y(t)$ and $X(t)$ as a function of time. Table 2 displays the constants of Method 3. The values of $X(0)$ are lower in seawater, which indicates that the degree of entrainment in all the cases is lower in this medium, which also correlates with the experimental data obtained following Methods 1 and 2. The values of constants $b$ indicate that the degree of entrainment decreases over time, which can be explained to be related to the loss of froth stability. As see in Table 2, the entrainment factors $X(0)$ using DF-250 are higher at all of the experimental conditions.

Table 2. Constants of Method 3 for MIBC and DF-250 at different $\mathrm{pH}$, and in fresh and seawater.

\begin{tabular}{ccccc}
\hline Frother & Solution & $\mathbf{p H}$ & $\boldsymbol{X ( 0 )}$ & $\boldsymbol{b}$ \\
\hline MIBC & Fresh Water & 9.0 & 0.12 & -0.0026 \\
MIBC & Fresh Water & 10.5 & 0.13 & -0.0029 \\
MIBC & Seawater & 9.0 & 0.074 & -0.0027 \\
MIBC & Seawater & 10.5 & 0.09 & -0.0030 \\
\hline Frother & Solution & $\mathbf{p H}$ & $\mathbf{X ( 0 )}$ & $\boldsymbol{b}$ \\
\hline DF-250 & Fresh Water & 9.0 & 0.18 & -0.0038 \\
DF-250 & Fresh Water & 10.5 & 0.21 & -0.0047 \\
DF-250 & Seawater & 9.0 & 0.13 & -0.0035 \\
DF-250 & Seawater & 10.5 & 0.14 & -0.0024 \\
\hline
\end{tabular}




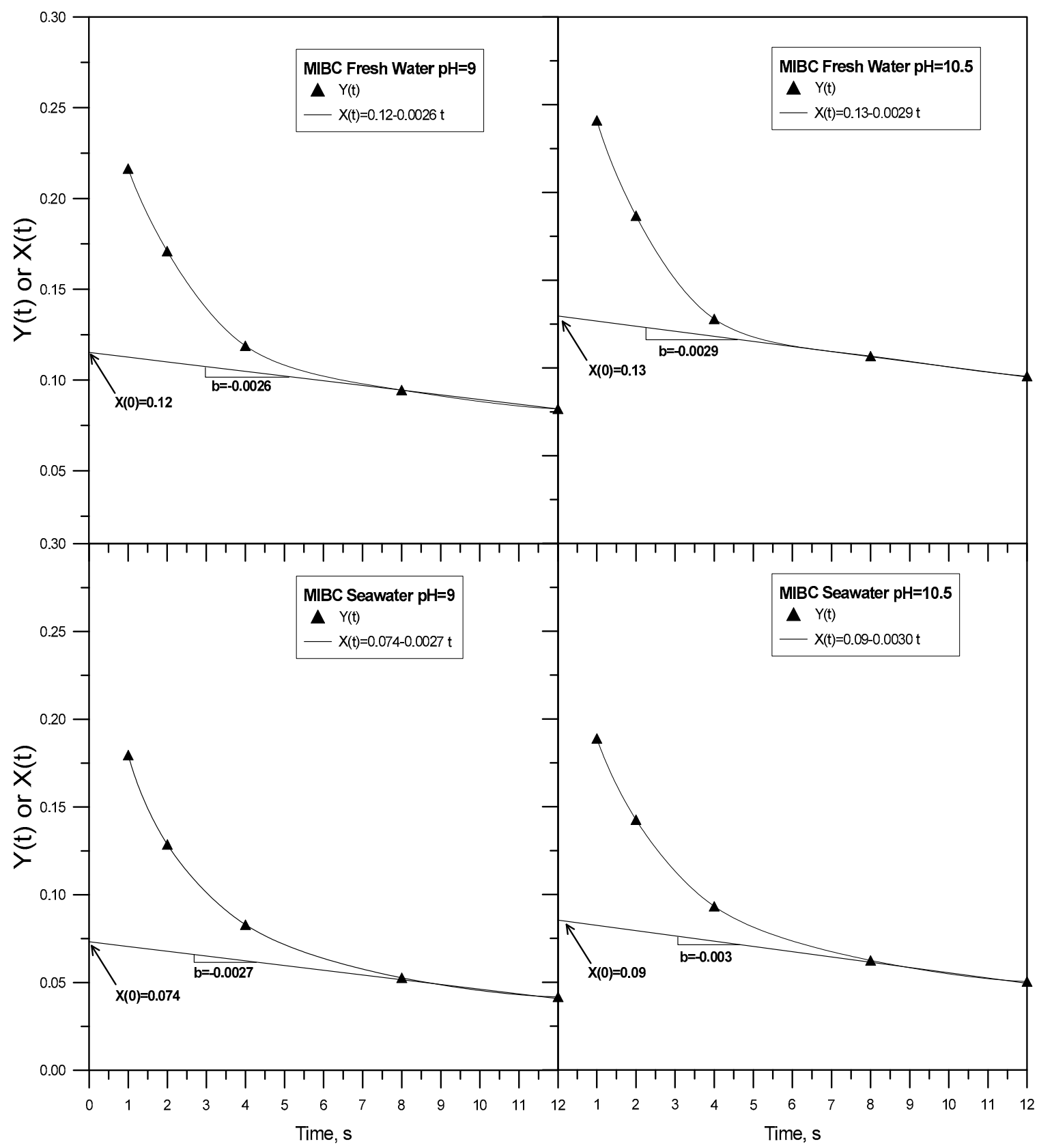

Figure 5. $Y(t)$ and $X(t)$ as a function of time. The tests were done in fresh and seawater, at $\mathrm{pH} 9$ and 10.5 , and using MIBC. 


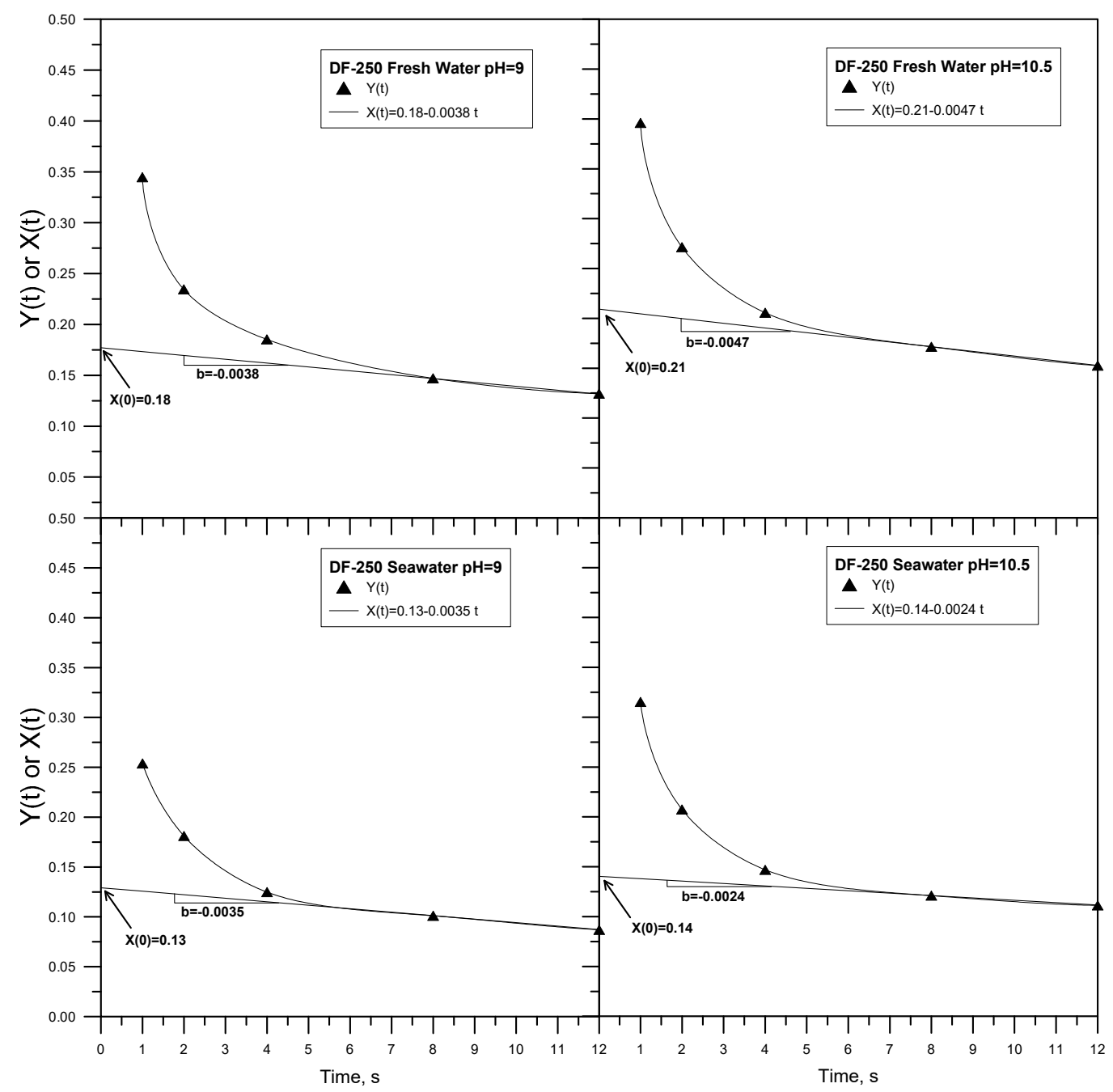

Figure 6. $Y(t)$ and $X(t)$ as a function of time. The tests were done in fresh and seawater, at $\mathrm{pH} 9$ and 10.5 , and using DF-250.

\section{Discussion}

Frothers are surface active compounds that are used in flotation to produce small and stable bubbles by inhibiting bubble coalescence [29-32]. The frothing properties change quite significantly depending on the type and concentration of ions in solution and on the frother chemistry used in the process [33]. Previous studies showed that the differences in surface activity between polypropylene glycols (e.g., DF-250) and MIBC become more important in $\mathrm{NaCl}$ electrolyte solutions, and that finer bubbles are generated in seawater [33]. It was also reported that inorganic salts not only inhibit bubble coalescence in the collection zone, but reduce bubble rise velocity, which leads to higher hold-up [34,35]. There are also some studies related to the froth behavior in seawater. Laskowski et al., 2014 [36], for example, studied frothability using a $\mathrm{Cu}$-Mo sulfide ore by measuring the froth equilibrium layer thickness in a bench scale flotation cell. These authors considered seawater and solutions of seawater cations (sodium, sulfate, magnesium, calcium, bicarbonate) in their experiments. The results showed that seawater was found to strongly depress frothability, and that the effect of $\mathrm{pH}$ on frothability over pH 9.5-11 was minor. Ramos et al., 2013 [37] showed that the presence of particles has a strong impact on the action of frothers, as they presented evidence indicating that the foamability of flotation frothers is promoted in seawater rather than in fresh water, but not frothability. It has to be noted that entrainment has been related to water recovery, but also to other variables such as the fundamental properties of the frothers used in flotation and their interaction with the ions dissolved in the aqueous 
medium used in the process $[4,5,38]$. It was reported that lower water recoveries are obtained when the water used in the process contains dissolved ions [39], which correlates with the experimental findings presented in this paper.

According to the bubble swarm theory, the amount of water reaching the layer below the pulp/froth interface should increase in seawater as the bubble size is expected to decrease, as previously reported [34,35]. The experimental data presented in this manuscript show that the degree of entrainment decreases in seawater with respect to freshwater, which is an indication of a lower recovery of liquid in the concentrate. Then, it is reasonable to think that the lower liquid recovery rate should be explained by the changes in froth that take place when seawater is used in the flotation tests. As summarized in the introduction, the amount of water that reports to the concentrate strongly depends on the size of the bubbles in the froth, and on the bursting rate of bubbles as they reach the cell lip [7-10]. More coalescence of bubbles in the froth, which leads to coarser bubbles and less air recovery, which means lower values of $\alpha$, reduces liquid recovery and thus entrainment [8,9]. Previous studies on frothability using Cu-Mo ores reported a depression of frothability in seawater, thus it is plausible to think that the decrease of the degree of entrainment in seawater presented in this work at $\mathrm{pH} 9$ and 10.5 with both frothers DF-250 and MIBC might be related to a reduction liquid recovery caused by a reduction of air recovery and/or more bubble coalescence in the froth. More experimental and theoretical work is needed to validate this hypothesis.

It is also important to consider in the discussion the possible effects on the lamellae thickness in seawater. As discussed, liquid mass transfer from the lamellae to the Plateau borders induces surfactant mass transfer and, as a manifestation of the Gibbs-Marangoni effects, a restoring liquid flow from the Plateau borders to the lamellae takes place, which stabilizes the film. Seawater contains high concentrations of ions, so it is also possible that surfactant diffusion/convection is hindered and, as a result, the surface tension gradients between the lamellae and Plateau borders might be reduced and thus the restoring liquid flow from the Plateau borders to the film. All these phenomena lead to more coalescence in the froth and, as discussed, less water recovery. The study of the effect of shear viscosity on the degree of entrainment in the process of flotation in seawater is out of the scope of this study, but deserves more research.

\section{Conclusions}

Three methods were used to quantify entrainment through flotation tests using a synthetic copper ore in fresh and seawater, and with MIBC and DF-250 as frothers. Although the experimental results indicate that the absolute values of entrainment measured fluctuate, the relative trends obtained under different experimental conditions allow reaching certain experimental conclusions regarding the effect of seawater on the degree of entrainment in the flotation process.

The experimental results presented in this manuscript indicate that the degree of entrainment decreases in seawater. Besides, water recovery is lower in the experiments with seawater regardless of the frother used in the experiments, which correlates with the observed low degrees of entrainment. It is proposed in this paper that reduction of entrainment and water recovery in seawater is explained by a reduction of air recovery and/or more bubble coalescence in the froth. It is also proposed that surfactant diffusion/convection from the lamellae to the Plateau borders in the froth is reduced in seawater, which reduces the surface tension gradients and thus the restoring liquid flow from the Plateau borders to the lamellae. More experimental and theoretical work is needed to validate these mechanisms.

Author Contributions: Conceptualization, writing—original draft preparation, writing—review and editing, supervision, project administration, funding acquisition, L.G.; conceptualization, methodology, investigation, writing - original draft preparation, F.B.; conceptualization, methodology, investigation, writing-original draft preparation, L.U.; conceptualization, writing-review, M.M. All authors have read and agreed to the published version of the manuscript.

Funding: This research was funded by ANID/FONDAP/15130015 project. 
Acknowledgments: Fernando Betancourt acknowledges support by CONICYT-Chile through the project AFB170001 of the PIA Program: Concurso Apoyo a Centros Científicos y Tecnológicos de Excelencia con Financiamiento Basal. Leopoldo Gutierrez also wants to thank ANID/FONDEF IDeA I+D/ID18I10117 project.

Conflicts of Interest: The authors declare no conflict of interest.

\section{References}

1. Smith, P.G.; Warren, L.J. Entrainment of particles into flotation froths. Miner. Process. Extr. Metall. Rev. 1989, 5, 123-145. [CrossRef]

2. Wang, L.; Peng, Y.; Runge, K.; Bradshaw, D. A review of entrainment: Mechanisms, contributing factors and modelling in flotation. Miner. Eng. 2015, 70, 77-91. [CrossRef]

3. Savassi, O.N.; Alexander, D.J.; Franzidis, J.P.; Manlapig, E.V. An empirical model for entrainment in industrial flotation plants. Miner. Eng. 1998, 11, 243-256. [CrossRef]

4. Melo, F.; Laskowski, J.S. Fundamental properties of flotation frothers and their effect on flotation. Miner. Eng. 2006, 19, 766-773. [CrossRef]

5. Melo, F.; Laskowski, J.S. Effect of frothers and solid particles on the rate of water transfer to froth. Int. J. Miner. Process. 2007, 84, 33-40. [CrossRef]

6. Kracht, W.; Orozco, Y.; Acuña, C. Effect of surfactant type on the entrainment factor and selectivity of flotation at laboratory scale. Miner. Eng. 2016, 92, 216-220. [CrossRef]

7. Neethling, S.J.; Cilliers, J.J. The entrainment factor in froth flotation: Model for particle size and other operating parameter effects. Int. J. Miner. Process. 2009, 93, 141-148. [CrossRef]

8. Neethling, S.J.; Lee, H.T.; Cilliers, J.J. The recovery of liquid from flowing foams. J. Phys. Condens. Matter 2003, 15, 1563-1576. [CrossRef]

9. Neethling, S.J.; Lee, H.T.; Cilliers, J.J. Simple relationships for predicting the recovery of liquid from flowing foams and froths. Miner. Eng. 2003, 16, 1123-1130. [CrossRef]

10. Neethling, S.J.; Brito-Parada, P. Predicting flotation behavior-The interaction between froth stability and performance. Miner. Eng. 2018, 120, 60-65. [CrossRef]

11. Neethling, S.J.; Cilliers, J.J.; Woodburn, E.T. Prediction of the water distribution in a flowing foam. Chem. Eng. Sci. 2000, 55, 4021-4028. [CrossRef]

12. Nguyen, A.V. Liquid drainage in single Plateau borders of foam. J. Colloid Interface Sci. 2002, 249, $194-199$. [CrossRef] [PubMed]

13. Stevenson, P. Dimensional analysis of foam drainage. Chem. Eng. Sci. 2006, 61, 4503-4510. [CrossRef]

14. Pugh, R.J. Foaming, foam films, antifoaming and defoaming. Adv. Colloid Interface Sci. 1996, 64, 67-142. [CrossRef]

15. Pugh, R.J. Experimental techniques for studying the structure of foams and froths. Adv. Colloid Interface Sci. 2005, 114-115, 239-251. [CrossRef]

16. Savassi, O.N. Direct Estimation of the Degree of Particles in Industrial Flotation Cells. Ph.D. Thesis, School of Engineering, The University of Queensland, Brisbane, Australia, 1998.

17. Trahar, W.J. A rational interpretation of the role of particle size in flotation. Int. J. Miner. Process. 1981, 8, 289-327. [CrossRef]

18. Warren, L.J. Determination of the contributions of true flotation and entrainment in batch flotation tests. Int. J. Miner. Process. 1985, 14, 33-44. [CrossRef]

19. Ross, V.E. Flotation and entrainment of particles during batch flotation tests. Miner. Eng. 1990, 3, $245-256$. [CrossRef]

20. Uribe, L.; Gutierrez, L.; Jerez, O. The depressing effect of clay minerals on the floatability of chalcopyrite. Miner. Process. Extr. Metall. Rev. 2016, 37, 227-235. [CrossRef]

21. Uribe, L.M. Efecto del Agua de Mar en la Recuperación de Minerales de Cobre Molibdeno por Procesos de Flotación. Ph.D. Thesis, Universidad de Concepcion, Concepción, Chile, 2017.

22. Rebolledo, E.; Laskowski, J.S.; Gutierrez, L.; Castro, S. Use of dispersants in flotation of molybdenite in seawater. Miner. Eng. 2017, 100, 71-74. [CrossRef]

23. Yepsen, R.; Gutierrez, L.; Laskowski, J.S. Flotation behavior of enargite in the process of flotation using seawater. Miner. Eng. 2019, 142, 105897. [CrossRef] 
24. Ramirez, A.; Gutierrez, L.; Laskowski, J.S. Sodium hexametaphosphate and sodium silicate as dispersants to reduce the negative effect of kaolinite on the flotation of chalcopyrite in seawater. Miner. Eng. 2018, 125, 10-14. [CrossRef]

25. Alvarez, A.; Gutierrez, L.; Laskowski, J.S. Use of polyethylene oxide to improve flotation of fine molybdenite. Miner. Eng. 2018, 127, 232-237. [CrossRef]

26. Castro, S. Proceso Para Pre-Tratar Agua de Mar y Otras Aguas Salinas Para su Utilización en Procesos Industriales. Universidad de Concepcion. Chilean Patent No. 00475/INAPI, 12 May 2010.

27. Castro, S. Challenges in flotation of Cu-Mo sulfide ores in sea water. In Water in Mineral Processing; Society for Mining, Metallurgy, and Exploration: Englewood, CO, USA, 2012; pp. 29-40.

28. Castro, S.; Rioseco, P.; Laskowski, J.S. Depression of molybdenite in sea water. In Proceedings of the 26th International Mineral Processing Congress, New Delhi, India, 24-28 September 2012; pp. 739-752.

29. Castro, S.; Uribe, L.; Laskowski, J.S. Depression of inherently hydrophobic minerals by hydrolysable metal cations: Molybdenite depression in seawater. In Proceedings of the XXVII International Mineral Processing Congress-IMPC, Santiago, Chile, 20-24 October 2014; pp. 20-24.

30. Cho, Y.S.; Laskowski, J.S. Effect of flotation frothers on bubble size and foam stability. Int. J. Miner. Process. 2002, 64, 69-80. [CrossRef]

31. Laskowski, J.S.; Cho, Y.S.; Ding, K. Effect of frothers on bubble size and foam stability in potash ore flotation systems. Can. J. Chem. Eng. 2003, 81, 63-69. [CrossRef]

32. Grau, R.A.; Laskowski, J.S.; Heiskanen, K. Effect of frothers on bubble size. Int. J. Miner. Process. 2005, 76, 225-233. [CrossRef]

33. Grau, R.A.; Laskowski, J.S. Role of frothers in bubble generation and coalescence in a mechanical flotation cell. Can. J. Chem. Eng. 2006, 84, 170-182. [CrossRef]

34. Castro, S.; Miranda, C.; Toledo, P.; Laskowski, J.S. Effect of frothers on bubble coalescence and foaming in electrolyte solutions and seawater. Int. J. Miner. Process. 2013, 124, 8-14. [CrossRef]

35. Quinn, J.J.; Kracht, W.; Gomez, C.O.; Gagnon, C.; Finch, J.A. Comparing the effect of salts and frother (MIBC) on gas dispersion and froth properties. Miner. Eng. 2007, 20, 1296-1302. [CrossRef]

36. Quinn, J.J.; Maldonado, M.; Gomez, C.O.; Finch, J.A. Experimental study on the shape-velocity relationship of an ellipsoidal bubble in inorganic salt solutions. Miner. Eng. 2014, 55, 5-10. [CrossRef]

37. Laskowski, J.S.; Castro, S.; Ramos, O. Effect of seawater main components on frothability in the flotation of cu-mo sulfide ore. Physicochem. Probl. Miner. Process. 2014, 50, 17-29.

38. Ramos, O.; Castro, S.; Laskowski, J.S. Copper-molybdenum ores flotation in sea water: Floatability and frothability. Miner. Eng. 2013, 53, 108-112. [CrossRef]

39. Iskra, J.; Laskowski, J.S. Frothers and frothing. In Frothing in Flotation II; Laskowski, J.S., Woodburn, E.T., Eds.; Gordon and Breach: New York, NY, USA, 1969; pp. 1-50. 